\title{
Livros e filhos: políticas de gênero e imaginação sociocultural da infância nas colunas de Clarice Lispector
}

\author{
ALEJANDRA J. JOSIOWICZ \\ Universidad de Buenos Aires \\ Consejo Nacional de Investigaciones Científicas y Técnicas
}

\begin{abstract}
This article studies the way in which the women's pages Clarice Lispector wrote between 1959 and 1961 for Correio da Manhã, under the pen name of Helen Palmer, and as ghost writer for fashion model Ilka Soares for Diário da Noite, reveal a transformation in the sociocultural imagination of childhood. In these columns, published in newspapers of wide circulation, Lispector's interest in child psychology, as well as her ideas about motherhood and child-rearing, become quite apparent. The women's pages crafted by Lispector unveil a social and historical paradigm shift in parental roles in line with the wider process of modernization, new consumption practices, and novel ideas about subjectivity that emerge during the 1960s in Brazil.
\end{abstract}

Keywords: Motherhood, child-rearing, press culture, gender, cultural studies

Em "A entrevista alegre," crônica publicada no Jornal do Brasil, Clarice Lispector narra que uma entrevistadora lhe perguntou: "o que mais me importava - se a maternidade ou a literatura. O modo imediato de saber a resposta foi eu me perguntar: se tivesse que escolher uma delas, que escolheria? A resposta era simples: eu desistiria da literatura. Nem tem dúvida que como mãe sou mais importante do que como escritora." A aparente simplicidade com que Lispector respondeu à pergunta encobre, de fato, uma profunda ambivalência. 
Escritora reconhecida e legitimada no ambiente literário brasileiro da época, cuja popularidade entre as classes médias começava a crescer graças às suas contribuições no jornal, em "A entrevista alegre," Lispector utilizou o meio público da crônica para reivindicar a suposta preeminência do espaço privado, íntimo, familiar. A figura convencional da mulher cuja prioridade absoluta é o espaço doméstico e a educação dos filhos funciona na crônica de um modo nada ingênuo. Ao contrário, opera no sentido de uma transgressão: a centralidade dada aos filhos por sobre os livros deve ser lida como um desafio à legitimação do meio literário e intelectual. Essa ambivalência constrói uma dinâmica de duplo questionamento, na qual a prioridade dada aos filhos desafia o prestígio literário e a centralidade da literatura-implícita, mas evidente na própria escrita da crônica - quebra o modelo familiar tradicional, através da figura da mulher intelectual, pública, independente e profissionalizada. Ao reivindicar um modelo sociocultural convencional de família, Lispector transgride o primado do prestígio e a legitimação do meio literário e, ao fazê-lo no âmbito público da crônica jornalística, reivindica o papel de mulher intelectual e escritora profissional. ${ }^{1}$ Nesta dinâmica, tanto a feminidade quanto a literatura são colocadas em questão, nenhuma resulta óbvia ou naturalizada.

Este trabalho examina a imaginação cultural da infância nas colunas femininas que Lispector escreveu entre 1959 e 1961, sob pseudônimo, através da ambivalência e da dupla desnaturalização que surge da justaposição entre um imaginário convencional e uma pulsão experimental em relação ao gênero e aos modelos familiares. Nelas, a infância constitui tanto um objeto de cuidado materno, de sua saúde, alimentação e crescimento, quanto um território desconhecido e um mistério a ser explorado pela mãe e escritora. A partir de uma perspectiva experimental, em um sentido estético mas também das políticas de gênero, as colunas questionam o modelo familiar tradicional e propõem pensar a criança como um exercício de exploração, descoberta e participação na vida dos filhos. Trata-se de um modelo familiar moderno, guiado pelas tendências cosmopolitas da sociedade de consumo, que não implica a eliminação das hierarquias entre os gêneros nem entre as idades, mas sim uma prática democrática e experimental na qual a mãe procura descobrir, explorar e estimular o desenvolvimento dos filhos.

\footnotetext{
${ }^{1}$ Para o tema da maternidade em Lispector, ver Mendes de Sousa e Williams.
} 
Os trabalhos críticos sobre a infância na obra de Lispector têm focalizado na análise da figura da criança como instância de transgressão (Dinis) e como manifestação da alteridade e da diferença (Wasserman, Central at the Margin e "Trabalho de mulher"). Outros estudos tem examinado suas crônicas e colunas sobre a infância em relação com as transformações de gênero e com a expansão do mercado cultural nas décadas de 1960 e 1970, como modos de quebrar as convenções literárias e transgredir o modelo reprodutivo (Josiowicz, La escritora e "Transformaciones de la infancia"). A infância é núcleo da ambivalência que a crítica de Lispector vem detectando na sua obra, a qual, por um lado, apresenta uma linguagem e uma perspectiva experimentais, coerente com uma imagem de escritora legitimada pelo campo literário e, por outro, inclui uma produção feita sob encomenda, ligada às demandas do mercado e o êxito comercial. Essa ambivalência na produção e na imagem da escritora teria continuidade no caráter ambíguo do gênero e do modelo da feminidade na sua obra: por um lado, um tipo de feminidade transgressiva das convenções e expectativas sociais; por outro, um modelo de mulher convencional, mãe e esposa dedicada, coerente com as expectativas do público massivo nessas décadas. Em direção análoga, a infância emerge tanto como instância de transgressão quanto como objeto de cuidados constantes por parte da mãe, núcleo do consumo das classes médias, cuja correta socialização é considerada central para o sucesso social da família como um todo. A produção jornalística de Lispector revela a justaposição entre esses dois modelos de infância: um ligado ao modelo familiar tradicional da maternidade e criança e outro marcado por uma concepção experimental da infância e da educação dos filhos, no qual aponta para o caráter contraditório e tensionado do processo de modernização social e cultural das décadas de 1960 e 1970.

\section{Entre a maternidade e a escrita: uma infância experimental}

Entre 1959 e 1961, Lispector contribuiu com vários tipos de publicações, através de colunas femininas, sob pseudônimo: redigiu a coluna "Feira de utilidades" duas vezes por semana no Correio da Manhã, entre agosto de 1959 e maio de 1961, sob o pseudônimo de Helen Palmer, e compôs uma seção seis vezes por semana com o título "Só para mulheres" no Diário da Noite, entre abril de 1960 
e março de 1961, como ghost writer da atriz de cinema e televisão Ilka Soares. ${ }^{2}$ Lispector produziu essas colunas em um momento muito significativo de sua trajetória intelectual e da sua biografia, dado que em 1959, separou-se de seu marido diplomata Maury Gurgel Valente, e decidiu voltar ao Brasil com os dois filhos (Moser). Tendo contraído matrimônio em 1943, Lispector tinha seguido ao marido em suas missões diplomáticas, morando fora do Brasil por quase duas décadas, primeiro em Nápoles, depois Berna, Torquay (Inglaterra) e Washington, DC, com breves estadas intermediárias no Rio de Janeiro. Em Berna, em 1948, nasceu Pedro, seu primeiro filho, e em Washington, em 1953, nasceu Paulo, o segundo. Lispector foi uma mãe atenta e cuidadosa do desenvolvimento psíquico e físico dos meninos, sensível às suas percepções, observações e comentários, preocupada com a escolha e adequação das babás.

Nas cartas que escreveu no período que vai desde sua primeira gravidez em 1948 até sua volta ao Brasil em 1959, os filhos foram uma temática constante: desde seu peso, sua fisionomia e detalhes de seu crescimento e alimentação até suas frases, expressões, gostos, travessuras, brigas e ocorrências (Lispector, Correspondências e Minhas queridas). ${ }^{3}$ Inclusive contando com a ajuda permanente de diferentes babás (europeias, norte-americanas e brasileiras), Lispector não deixou de cuidar pessoalmente dos detalhes de sua educação e não foi uma mãe distante nem despreocupada: as cartas mencionam consultas a médicos, psicólogos e serviços pedagógicos para os dois filhos. ${ }^{4}$ Sobre Pedro anota, em carta de 1950: "ele fala as poucas palavras aprendidas como um caboclo falaria inglês. Ele diz: gude morningue" (Correspondências 190). Em outra do mesmo ano: "Ele está muito bem, cheio de palavras novas, mas tudo em português ... Vive faminto, conversando sobre comida, "carninha gostosa," "peixinho ótimo," etc. ... E fala tanto que se ele de um modo geral não fosse um filho eu ficava cansada" (Minhas queridas 235). Em carta de 1953, escreve que Pedro: "Está muito carinhoso comigo, diz que vai me dar uma casa bem grande, com muitas comidas dentro. Eu preferiria que ele me desse mais uma empregada"

\footnotetext{
2 Parte das colunas foram publicadas em uma versão organizada por Aparecida Maria Nunes em dois volumes, Correio feminino (2006) e Só para mulheres: conselhos, receitas e segredos (2008).

${ }^{3} \mathrm{O}$ cuidado dos filhos aparece também nas cartas que envia aos sogros desde Berna, as quais se encontram no Acervo Clarice Lispector da Fundação Casa de Rui Barbosa.

${ }^{4}$ Nesse período, embora cuide dos dois filhos por igual, Lispector mostra preocupação mais aguda pelo desenvolvimento psíquico de seu filho mais velho, Pedro, que posteriormente, na adolescência, desenvolveria esquizofrenia.
} 
(Minhas queridas 242). Posteriormente, em carta de 1956, conta que ele disse: "For men must work and women must weep" (Correspondências 203), frase que a surpreendeu por seu caráter literário e que, efetivamente, era parte de uma poesia que Pedro leu numa enciclopédia. Sobre Paulo, observa, em carta de 1953: "Paulinho está de uma preciosidade tranquila e satisfeita. Imaginem que ele está dando, sozinho, uns 6 a 8 passos! E fala "by-by," "cass" ou "cacau" (para dizer: caiu!)" (Minhas queridas 247). Em outra, de 1956, afirma: "Ele, aliás, ainda em fase de ciúme declarado. Me disse: eu quero que você só tenha um filho, eu. Eu disse: e Pedrinho? Ele: manda ele para a escola!" (Minhas queridas 271); e: "Paulinho me perguntou que é que eu faria se Deus tivesse me dado, em vez de boys, uma árvore. Achei que seria provavelmente mais fácil" (Minhas queridas 277). As cartas revelam a imagem de uma mãe interessada e carinhosa com os filhos, mas que não segue ao pé da letra o modelo de maternidade tradicional: não tem embaraço em expressar seu cansaço deles, menciona as dificuldades da criança, a necessidade de ter ajuda extra (como mais empregadas) e está longe de idealizar seu papel. Além disso, essa mãe é uma observadora atenta da linguagem dos filhos, não só como mãe orgulhosa de seu desenvolvimento mas também como uma escritora que escuta com particular sensibilidade estética e investiga seu psiquismo, seu pensamento e os modos de sua expressão.

Embora não tivesse podido amamentar ao primeiro filho, amamentou ao segundo, sobre o qual afirma: "Eu estou continuando a amamentá-lo . . . estou tão espantada de estar amamentando. Nunca esperei” (Minhas queridas 242). Essa estranheza diante dos fatos da maternidade-no caso, diante da amamentação - se conjuga com uma perspectiva estética e transcendental para observar aos filhos. Assim, afirma: "Juquinha está muito engraçado e muito voluntarioso. Ele presta atenção a tudo. Não entendo mesmo, mistério de uma criança .. . Um corpinho desse tamanho existe com grande evidencia uma almazinha. Da onde vem? Não responda" (Minhas queridas 212-13). Os filhos aparecem como verdadeiros mistérios, segredos transcendentes que a escritoramãe descobre ao interior do âmbito doméstico e familiar.

Em muitas cartas desses anos, são os próprios filhos os que tomam a palavra e escrevem ou fazem desenhos para o destinatário: o espaço central que Lispector lhes dedica revela o propósito de encorajá-los a ter sua própria expressão, sua própria voz, conjugando o cuidado carinhoso da mãe com o olhar estético da escritora. Em carta de 1955 às irmãs Tania Kaufmann e Elisa Lispector, afirma: 
Ontem, Paulinho escreveu duas cartas, uma para você, Elisa, e outra para você, Tania. Não mando porque são enormes e muito herméticas, isto é, nelas tudo é simbólico a um ponto que vocês sinceramente não "receberiam" a "mensagem" dele. Aliás ele é um escritor muito intenso: o lápis às vezes fura o papel. E, ao mesmo tempo, é capaz de descrever as emoções mais delicadas: às vezes o traço dele é tão fino e apagado que a 'mensagem' deveria ser lida ao microscópio. (Minhas queridas 261-62; ênfase minha)

Embora nessa carta Lispector não incorpore a produção dos próprios filhos, descreve-os em um sentido literário, como escritores, capazes de simbolização, de transmitir emoções e mensagens com uma alta carga estética. Isto é ainda mais evidente nas cartas que incorporam diretamente desenhos e palavras escritas pelos filhos. ${ }^{5}$ Afirma em carta a Mafalda Verissimo: "esta carta de Paulo . . . foi inteiramente espontânea. Ele próprio bateu 'texto' à máquina e veio me dizer This letter to Mafalda is about pipi and popô, because one day she talked to me by telephone and said to me those bad words. That's why I'm sending her bad words too. (De modo que, onde se lê 'csd fdx ppp', leia-se 'pipi e popô')" (Correspondências 218). E, em outra: "Paulinho queria escrever para você (I'm going to write a letter to ... Mafalda) e até me ditou os dizeres. Achei estranho essa história de 'Dear Prato' [dedicatória da carta] mas ele insistiu-depois explicou que era porque pretendia dar a você, um dia, um prato de presente. Como você vê, é absolutamente lógico" (Correpondências 222). A escritora-mãe deixa entrar a palavra e o traço dos filhos como um ready-made, isso é, sem corrigi-las nem modificá-las, sem nenhum tipo de mediação adulta.

Com uma perspectiva que conjuga a maternidade e a literatura, Lispector valoriza a produção espontânea dos filhos, incorpora-a e a lê como contendo uma lógica e um valor literário próprios, como se eles fossem escritores, criadores e artistas por próprio direito. Trata-se de uma concepção experimental da infância como detentora de um senso estético, combinada com uma prática pedagógica também experimental, que estimula nos filhos a expressão de seu rico mundo

\footnotetext{
${ }^{5}$ Ver por exemplo as cartas de 27 e 30 de março de 1957 (Correspondências 206-23).
} 
interior, de sua espontaneidade, na qual os pais têm a capacidade de atender suas manifestações, entrar no seu mundo sem ideias prévias ou objetivos fixos e de acompanhar, respeitosamente e sem censura, sua lógica e seu modo de pensar. De fato, Lispector levou um registro minucioso das histórias inventadas por seus filhos e guardou vários contos redigidos por Paulo (além de cartas, exercícios escolares e desenhos), em inglês e em português. ${ }^{6}$

Já de volta no Brasil, em 1959, Lispector mudou-se a um apartamento no Rio de Janeiro, no bairro do Leme, e enfrentou as dificuldades materiais e financeiras e os prejuízos sociais próprios da mulher separada e com dois filhos. Lispector era sensível ao olhar dos outros e às convenções sociais e provavelmente sentiu algum grau de vergonha e estranheza pelo fato de estar separada em uma sociedade que estigmatizava o divórcio. Nesse sentido, sua volta ao Brasil e sua separação significou um divisor de águas que ressaltou a contradição, em alguma medida existente no período prévio, entre o papel convencional da mulher, como esposa e mãe de família, e um horizonte que implicava a transgressão desses parâmetros sociais e de gênero a partir da figura da escritora profissional. ${ }^{7}$ Essa ambivalência traduziu-se numa perspectiva também dupla diante da infância, como objeto de cuidado permanente e atento da mãe, e ao mesmo tempo como objeto de interesse experimental da escritora, observadora de seu psiquismo, sua linguagem e seu pensamento. Nesse duplo sentido, as crianças tornaram-se, na produção jornalística de Lispector desses anos, verdadeiros mistérios a serem descobertos ao interior do âmbito doméstico.

\section{A infância e as transformações do imaginário sociocultural}

No Brasil, as décadas de 1950-1960 foram um período de emergência da sociedade de consumo e fortalecimento da classe média, sobretudo nos centros urbanos. A cultura impressa massiva surgida na primeira metade do século XX, modernizou-se e organizou-se de forma capitalista e industrial, incluindo vários segmentos da indústria cultural, como as revistas e os jornais com seus

\footnotetext{
${ }^{6}$ Esses materiais foram consultados no Acervo Clarice Lispector na Fundação Casa de Rui Barbosa.

${ }^{7}$ A bibliografia sobre a questão de gênero em Lispector é muito ampla: ver, por exemplo, Peixoto. Para uma leitura da questão de gênero nas colunas, ver também Lobo. Mais recentemente, Mariela Méndez tem analisado a coluna feminina de Lispector na perspectiva dos estudos de gênero e dos estudos queer, como desnaturalização do feminino, que aparece como máscara e disfarce.
} 
suplementos e semanários (Barbosa). A imprensa articulou-se cada vez mais ao discurso publicitário, ao mesmo tempo que se especializava em torno dos interesses diversificados do público consumidor, feminino, masculino e infantil (De Luca, “A grande imprensa"). Na década de 1950, os "anos dourados" da imprensa feminina, as publicações para mulheres revelavam a imagem de uma mulher que tinha acesso aos hábitos de consumo associados às novas tecnologias. Era a mulher casada, mãe, de classe média, urbana, capaz de escolher dentre uma ampla variedade de produtos: alimentos, produtos de higiene, roupas, remédios, eletrodomésticos (De Luca, "Mulher em revista" 456).

Embora tenha havido um progressivo aumento da participação da mulher no mercado de trabalho e um maior acesso à educação formal, persistiu, em grande medida, uma divisão tradicional dos papéis de gênero e uma concepção da mulher como dedicada à maternidade e à esfera doméstica, consagrada a seu marido e educadora de seus filhos (Basanezi Pinsky 609). O desquite ou separação foi instituído em 1942 e só em 1977 seria instaurado o divórcio, o qual fazia dos filhos de pais separados frutos estigmatizados de um "lar desfeito" e da mulher separada, mal vista, objeto de estrita vigilância moral (Basanezi Pinsky 610). Só a partir de fins da década de 1960 e 1970, houve uma progressiva transformação dos modelos socioculturais e dos papéis de gênero pela qual a mulher foi pensada fora do horizonte exclusivo do casamento e da maternidade e a juventude emergiu como ator social fundamental (Berquó 413-14). Começam a ser abordados em forma pública, nos meios massivos de difusão, na rádio, na televisão, nas revistas e os jornais, temas como a separação, a sexualidade e os métodos de contracepção ("Mulher em revista"), assim como a educação dos filhos, os novos modelos de criança e a nova concepção da juventude. Embora o casamento e a família elementar se conservassem como padrões culturais balizadores das relações sociais, houve uma transformação no modo de conceber a relação entre seus membros: os papéis fixos e imutáveis de homens e mulheres, pais e filhos, começaram a ser questionados em favor de novos valores morais, considerados "modernos," como o autoconhecimento, a autonomia e a independência (Santos).

A infância foi um dos eixos fundamentais nesta transformação sociocultural dos modelos familiares e dos papéis de gênero: incorporada ao longo da primeira metade do século ao mundo do consumo cultural moderno, a partir de 1950 e 1960 começou a ser interpelada pelas estratégias publicitárias cada vez mais 
diretamente como participante do consumo (Brites). Tratou-se de um novo paradigma de compreensão da individualidade dos filhos, que combinou o biológico e o psicológico - no qual a mãe começa a ser considerada como base do equilíbrio psíquico e subjetivo dos filhos, responsável de entender a experiência infantil. O novo modelo fez das crianças verdadeiros interrogantes, objetos de investigação, de observação pormenorizada e atenta por parte de pais, professores, psicólogos, escritores e intelectuais. Para psicólogos, psicanalistas e intelectuais, a infância tornou-se chave para explorar a história individual, explicar desordens e neuroses, assim como um modo de liberar-se dos traumas psíquicos e de desenvolver as capacidades criativas do indivíduo (Russo).

\section{A jornalista e sua biblioteca cosmopolita}

Foi a partir da década de 1950 que se iniciou a produção jornalística de Lispector orientada ao público feminino, quando Rubem Braga a convidou a participar da equipe do tabloide Comício, sob o pseudônimo de Tereza Quadros, com a coluna titulada "Entre Mulheres" (Nunes). Em 1959, também foi convidada a participar da influente revista Senhor e, a partir de 1961, teve uma coluna em cada número, com o título de "Children's Corner," assinada com seu próprio nome, a qual the traria considerável popularidade no meio cultural e literário brasileiro (Moser 276). Simultaneamente a essa publicação destinada ao público literário e cultural, ela escreveu uma coluna feminina no Correio da Manhã sob o pseudônimo de Helen Palmer. Para essa coluna, Lispector assinou um contrato com a firma Pond's, o qual requeria dela um tom "informado sem ser sábia," razoavelmente inteligente, mas por momentos indeciso, como se contasse com a opinião da leitora, evitando abrumá-la com excessivas informações. ${ }^{8} \mathrm{O}$ contrato exigia da escritora um papel ativo na tarefa de aportar ideias para a identificação e imposição dos produtos que se desejava vender (os cremes Pond's), ressaltando sua eficácia para o público feminino. No entanto, não seria correto considerar as colunas como simples imposições editoriais ou comerciais, dado que estão em relação de continuidade com o resto da obra e da trajetória de Lispector, na qual aparecem similares tensões e contradições entre modelos de feminidade e de infância: entre a figura da mulher esposa e mãe, preocupada pela felicidade do

\footnotetext{
${ }^{8} \mathrm{O}$ contrato original consta no Arquivo Clarice Lispector na Fundação Casa de Rui Barbosa.
} 
marido e dos filhos, a mulher "moderna," consumidora de bens e produtos, e a mulher independente das convenções sociais e capaz de questionar seus limites; entre a infância como objeto de cuidado materno e como modalidade de experimentação estética e de questionamento dos modelos tradicionais.

Na mesma época, Lispector recebeu o convite por parte de Alberto Dines para redigir a coluna "Só para mulheres," seis vezes por semana, no tabloide Diário da Noite, sob o pseudônimo da atriz de televisão e cinema Ilka Soares, a qual foi um sucesso, em grande parte graças à dedicação de Clarice e a seu acesso a revistas internacionais, como Bunte, Paris Match e Jour de France, das quais utilizava materiais como fotografias e ilustrações (Nunes 3). Para confecção de ambas colunas destinadas ao público feminino, Lispector utilizou uma biblioteca transnacional e cosmopolita composta por uma bibliografia das mais diversas. Alguns livros, destinados especificamente ao público feminino, incluíam conselhos de beleza e vestuário, receitas, exercícios físicos, dietas e informações sobre saúde: textos como Enciclopédia da mulher e da família (1971), The Homemaker's Encyclopedia: Personal Beauty and Charm (1952), A Arte de beber e recepcionar (1957), Saúde e vida longa pela boa alimentação (1959), e Beleza e personalidade: o livro azul da mulher (1945). ${ }^{9}$ Trata-se de livros destinados a ajudar à mulher no cuidado da beleza, do lar e na economia doméstica, assim como no cultivo da sua personalidade e de sua vida social. Por outro lado, Lispector tinha lido uma ampla bibliografia sobre psicologia, sexualidade e educação dos filhos: folhetos, livros e best-sellers que incluem textos de psicologia e autoconhecimento, como o escrito pela psicóloga feminista Karen Horney ou por Erich Fromm, ${ }^{10}$ textos de auto-ajuda psicológica, ${ }^{11}$ de psicanálise, sexologia e ainda, manuais de auto-ajuda para mulheres, como Your Power as a Woman: How to Develop and Use It (1957), manuais de educação sexual, como What to Tell Your Children about Sex. Prepared by the Child Study Association of America (1959), manuais de educação dos filhos, como The Aims of Education: A Mentor Book. (1952), Tell me: Answers to 261 Typical Questions

\footnotetext{
${ }^{9}$ Essa bibliografia encontra-se na Biblioteca de Clarice Lispector, que é parte do Acervo Clarice Lispector no Instituto Moreira Salles.

${ }^{10}$ Are You Considering Psychoanalysis? (1946), da pioneira da psicologia feminista Karen Horney, El miedo a la libertad (1957) e Análise do homem (1960), do também psicanalista Erich Fromm. ${ }^{11}$ How to Make Psychology Work for You? (1957), Your Personality (1956), Domine o seu sistema nervoso (1961), Liberte a sua personalidade: uma nova maneira de dar mais vida à sua vida (1960), e Como vencer os sentimentos negativos (1967), do médico Maxwell Maltz.
} 
Asked by Growing Boys and Girls (1947), enciclopédias infantis, como The Book of Knowledge: the Children's Encyclopedia. (1955) e Child Behavior (1955) da pediatra Frances Ilg, com perguntas e respostas sobre o comportamento infantil. ${ }^{12}$

Nesta bibliografia, aparece a imagem da mulher moderna, que cuida de sua beleza, de sua aparência física e seu vestuário, o que é a base de sua sociabilidade bem sucedida. Mas também trata-se de uma mulher altamente reflexiva: que explora sua própria individualidade, seu psiquismo e sua sexualidade, e que reflete sobre os modos de lidar com a subjetividade de seus filhos, sua educação, sua sexualidade, sua conduta e seu pensamento. Nas anotações que a escritora fez nesses volumes, sobressai a questão do papel dos pais no estímulo da formação da personalidade dos filhos e no modo de assegurar sua bem sucedida socialização. Lispector sublinha profusamente as partes referentes à transformação dos modelos de criança, ao questionamento da autoridade parental e ao novo protagonismo dos filhos e suas escolhas individuais. Segundo esses textos, os pais deveriam abandonar atitudes autoritárias, que debilitariam a personalidade dos filhos, e deveriam privilegiar a confiança, a compreensão e a tolerância, capazes de estimular seu desenvolvimento. Os adultos deveriam auxiliar os filhos na realização de suas potencialidades, a ser espontâneos e originais, em lugar de tentar impor normas ou objetivos fixos, o que seria essencial para sua inserção em uma sociedade em mudança. Os textos também ressaltam a importância de falar abertamente sobre sexo com as crianças, como um modo de assegurar o saudável desenvolvimento de sua capacidade sexual e amorosa. Por seu caráter cosmopolita, a biblioteca de Lispector revela a enorme influência e o prestígio dos valores socioculturais originados nos Estados Unidos e na Europa - sobretudo a literatura de auto-ajuda, a literatura psicológica e os textos sobre educação e criança - fundamentais para compreender os modelos de mulher e de infância que circularam na imprensa e no mercado cultural do Brasil.

\section{Helen Palmer e Ilka Soares}

É possível evidenciar o impacto dessas leituras, que apontam para mudanças socioculturais no modo de pensar a infância e a feminidade, nas colunas

\footnotetext{
${ }^{12}$ Essa bibliografia encontra-se na Biblioteca de Clarice Lispector que é parte do Acervo Clarice Lispector no Instituto Moreira Salles.
} 
femininas que Lispector escreveu no Correio da Manhã entre agosto de 1959 e maio de 1961, sob o pseudônimo de Helen Palmer, e nas que publicou no Diário da Noite entre abril de 1960 e março de 1961 sob o pseudônimo da modelo e atriz Ilka Soares. No primeiro caso, na coluna "Feira de utilidades," aparece um modelo de mulher que, embora continue atrelado ao papel de mãe e esposa encarregada do âmbito doméstico, preocupada por satisfazer ao marido e aos filhos, é uma mulher "esclarecida," "moderna e interessante," que "acompanha o ritmo da vida atual" ("A mulher esclarecida"). Lispector não questiona o modelo de feminidade hegemônico; embora reconheça que existem preconceitos, expressa irritação perante as reivindicações do feminismo e afirma que "a mulher não foi aprisionada pelo homem, mas pela sua própria natureza fisiológica" ("A mulher e o preconceito"). Sem subverter os parâmetros de feminidade tradicional, Palmer chama a atenção para o processo de modernização do papel da mulher e surgimento de um novo modelo de feminidade, altamente reflexivo e capaz de auto-análise, na qual o discurso de auto-ajuda de origem norteamericana cumpre um papel fundamental. O próprio pseudônimo, Helen Palmer, aponta para o prestígio da língua inglesa como via de modernização cultural. De fato, a coluna menciona a "importante descoberta" da "pílula preventiva por via bucal" "vendida oficialmente nos Estados Unidos" ("Importante descoberta"): a mulher moderna, guiada pelas últimas tendências socioculturais cosmopolitas, é capaz de falar de sua sexualidade e de métodos contraceptivos. Portanto, concebe a maternidade não como uma imposição ou um fato da natureza mas como uma escolha consciente, relativamente livre e individual.

No caso da coluna "Só para mulheres," há uma intenção evidente de se aproximar da leitora, como mulher moderna, interpelando seus interesses e preocupações. Soares responde com freqüência cartas de leitoras de todo o Estado do Rio de Janeiro procurando todo tipo de sugestões e conselhos. A coluna transmite um modelo de mulher preocupada com sua beleza, mas que privilegia sua personalidade e sua originalidade por sobre qualquer moda: "moda é tendência, tendência geral a ser adaptada por cada uma de nós, a ser usada com prazer e não a nos escravizar . . . Lembre-se: moda é moda, mas quem manda mesmo é você. E quem escolhe também” (“A moda”). Mais uma vez, é importante ressaltar o prestígio das tendências culturais e de consumo internacional, sobretudo dos Estados Unidos. Para Ilka Soares, a identidade feminina está atrelada à maternidade, mas não se trata de uma mãe afastada do 
mundo secular: ela está inserta na moderna sociedade de consumo. Afirma Ilka Soares no artigo "Dia das mães":

Bem sei que a ideia de tal dia no ano pode mesmo ter vindo dos comerciantes que vendem presentes a não acabar. Mas a ideia pegou. Nós a aceitamos sem vacilar, como se a esperássemos. Então, pois, vivam os comerciantes. Eles lucram, mas as mães também. E os filhos também pois filhos também gostam de dar, de demonstrar, de ter chance de abençoar.

A mãe e o próprio filho se beneficiam materialmente, tanto quanto a própria indústria cultural e do consumo, com a modernização do laço familiar.

Esse modelo de mulher-mãe também é altamente reflexivo no que diz respeito à educação dos filhos e utiliza os conhecimentos mais modernos sobre a saúde física, a alimentação e o crescimento da criança: a importância pedagógica dos brinquedos, a necessidade do asseio, da higiene, do exercício ao ar livre, da vacinação e da nutrição natural, a base de vitaminas e minerais. Neste ponto, ela segue os ditames dos higienistas brasileiros que, desde a primeira metade do século, recomendavam a prática de esportes, atividades físicas e boa alimentação como modo de prevenir doenças e assegurar a saúde e o bem-estar infantil (Lima e Hochman 2004). Essa mãe é uma verdadeira enfermeira ao interior do âmbito doméstico, que possui medicamentos e outros itens necessários para resolver qualquer imprevisto que possa afetar a saúde física das crianças. Afirma Palmer: "A mãe cuidadosa terá uma farmácia completa em casa, com todos os medicamentos de urgência, além de gases e ataduras. Deve ter algum conhecimento de enfermagem de urgência, para aplicá-lo na ocasião necessária. E acima de tudo precisa ter calma para enfrentar a situação desagradável" ("A criança persegue o perigo"). Por seu lado, Soares inaugura uma seção, que dura vários números, com o título "Na hora da aflição, o que você faria?" com perguntas (e respostas) para que as leitoras vejam se sabem o que fazer em caso de emergências médicas com seus bebês.

Palmer e Soares são consumidoras espertas de todo tipo de produtos destinados ao bem estar dos filhos: desde medicamentos, roupas e sapatos, até móveis, decorações, brinquedos eletrônicos, bonecos de Disney e todo tipo de bens para o consumo infantil. Soares cria a seção "Eu e você nas compras," na 
qual recomenda "Dê um presente aos seus filhos," um macaco ou um cachorro de pilha, uma máquina de filmar infantil, um avião com luzes. A coluna inclui fotografias de moda para mães e filhas, e anuncia a existência de uma "Boutique" para crianças de até 5 anos de idade. Como parte de uma iconografia com crianças e bebês que aparecem em suas páginas ligados a diferentes práticas de consumo, a coluna incorpora uma fotografia de grande tamanho de duas meninas em biquíni com o título "Elas também querem a moda" na qual as meninas aparecem como consumidoras por próprio direito, "femininas" e "elegantes" “desde cedo." Esses bens de consumo não aparecem na maior parte das vezes de modo frívolo mas como essenciais para assegurar a saúde física e o bem-estar das crianças. Palmer afirma que a mãe deve privilegiar o conhecimento especializado e a opinião qualificada dos médicos por sobre o saber leigo, popular e oral, das vizinhas e outros indivíduos. A interação mãe-médico deve ser prioritária e constante, e substitui a opinião do senso comum e da tradição familiar.

As colunas vão além das preocupações com a saúde física e incorporam as teorias pedagógicas e psicológicas mais modernas: a mãe torna-se uma verdadeira psicóloga e uma educadora no interior do lar. Palmer questiona os métodos de educação tradicionais, nos quais os filhos eram moldados de acordo com ideias e objetivos predeterminados e pais e filhos estavam separados por uma distância hierárquica, e propõe uma relação de compreensão e apoio entre eles, na qual os pais descobrem a personalidade dos filhos para assim estimulálos adequadamente. Assim, ela afirma que "ser mãe":

Não é sofrer as dores do parto e depois esquecer o fruto de suas entranhas, deixando-o entregue a si mesmo. Uma verdadeira mulher e mãe sabe que seus deveres vão além de alimentar, enfeitar e agasalhar o seu filho. Antes de tudo, deve dar-lhe amor. Amor que é devoção, cuidado, orientação, e sobretudo participação em seus problemas e suas dificuldades. Toda mãe deve conhecer o filho que trouxe ao mundo, e isso consegue chegando-se a ele, ouvindo-lhe as primeiras queixas e os primeiros desejos. Deixá-lo inteiramente entregue aos cuidados de uma estranha, de uma babá, vendo-o por minutos, apenas, 
beijando-o apressadamente no momento de exibi-lo às visitas, é mais do que erro. É crime. ("Ser mãe”)

Trata-se de uma transformação nos modos de pensar a maternidade e a infância, já não como simples resultado do fato biológico do nascimento nem da necessidade física da nutrição, mas como uma proximidade afetiva constante, um tipo de atenção permanente e de participação na vida da criança. A subjetividade dos filhos torna-se objeto de estudo da mãe, quem descobre quem ele é, seus desejos profundos, e não tenta impor as normas ou convenções que considera corretas. A maternidade é concebida como uma prática experimental, de observação das crianças, na qual se deve descartar qualquer preconceito ou ideia sobre elas. Por isso, deve ser a própria mãe, e não uma babá, a encarregada do cuidado dos filhos: a maternidade, longe de uma questão pragmática, implicaria um profundo envolvimento psíquico e afetivo, como uma jornada de descoberta que a mãe inicia junto ao filho, cujo objetivo é o desenvolvimento do potencial que lhe é próprio, como um projeto reflexivo. Esse tipo de educação é coerente com uma sociedade regulada pela livre iniciativa individual, pela competição e a especialização, em lugar do respeito às tradições herdadas e à autoridade. Afirma Palmer: "A criança, tanto quanto permite sua idade e compreensão, deve ser ensinada a se adaptar às diversas situações com que se defronta, para que seu êxito futuro seja completo, proporcionando-lhe uma vida mais feliz" (“Educação"). Esse modelo de educação sem parâmetros fixos e predeterminados, guiada pelos desejos e as necessidades do próprio educando, que implica uma entrega dedicada e experimental do adulto, e a valoração da subjetividade e a originalidade do filho, seria capaz de prevenir o desajustamento social em uma sociedade carente de tradições herdadas.

Como Palmer afirma, o novo paradigma educativo está guiado pelas experiências da própria criança, que se vê como "um ser em formação" que "está sempre se transformando," como resultado de suas interações, muitas vezes desafiadoras, com um mundo em constante mudança. Para isso, os pais devem estar atentos às suas manifestações, devem estudá-los detidamente, escutá-los, transmiti-lhes confiança e compreensão, abandonar seu lugar de "fria autoridade," de portadores de ordens e regras de conduta, para ser "amigos," "companheiros," "confidentes" de seus filhos, que participam de seus interesses e desejos ("Amizade valiosa"). 
Palmer também sugere como lidar com os adolescentes, questão da maior importância social e familiar naquelas décadas: para prevenir o desajustamento e a rebeldia dos jovens e das jovens, ela recomenda, em lugar de castigos e normas disciplinares, a aproximação amistosa da mãe, que deve conversar e ouvir a sua filha, que lhe deve dar sua "atenção permanente," sua escuta e compreensão ("Filhas modernas e rebeldes"). Do mesmo modo, Soares, em artigo titulado "A criança independente," enfatiza a necessidade de que os pais "modernos" estimulem a independência, a confiança em si mesmos e a iniciativa própria dos filhos como seres responsáveis e com juízo próprio, mostrando interesse nas suas opiniões e seus métodos e deixando que eles experimentem por si mesmos. A maior independência concedida à criança como parte do paradigma moderno de educação implica uma série de desafios "físicos e psicológicos," e os pais devem ajudar aos filhos a atravessar essas situações, através da compreensão e não do castigo, através do diálogo e da persuasão e não da severidade ou da obediência.

Também sublinha a importância de que a mãe estimule a sociabilidade de seus filhos, que eles possam interagir com outras pessoas sem conflitos, e tenham amizades, o que revelaria seu correto ajustamento ao meio social. Os pais, segundo Palmer, devem abandonar os "princípios clássicos" e adotar a "moderna pedagogia," baseada na liberdade; devem sair de sua área de conforto e entrar na "cultura especializada" da educação moderna, cujo objetivo é "procurar a vocação da criança para que ela aprenda com maior facilidade" ("Educação dos filhos"). Quanto ao grau de liberdade que devem receber os filhos, Palmer recomenda administrá-la para que não seja excessiva, para que os filhos contem com o acompanhamento e o apoio dos pais, e não se sintam abandonados. Em lugar de um paradigma normativo, trata-se de um paradigma com foco no filho e no modo pelo qual a educação pode ajudar no seu desenvolvimento. Palmer recomenda não fazer concessões às vontades do filho, e estabelecer limites claros, mas essa firmeza é pensada como benéfica para a criança, núcleo da sua educação. Segundo esse paradigma, a mãe deve ser uma verdadeira pedagoga e psicóloga ao interior do âmbito doméstico, que estimula o desenvolvimento da individualidade dos filhos, e tem foco nas suas necessidades.

A centralidade do psiquismo neste paradigma é tanta que inclusive os comportamentos da criança que décadas atrás teriam sido interpretados como simples problemas físicos (fome, vômitos, cólicas, etc.) são pensados agora como sintomas inconscientes de seu psiquismo. Palmer, leitora e conhecedora das 
teorias psicológicas e psicanalíticas da época, afirma que o bebê possui desde o nascimento um mundo emotivo e um psiquismo próprios e que o estado psíquico da mãe poderia influenciá-lo desde cedo, o que reforça ainda mais o papel da mãe como responsável de seu bem-estar: "A mãe, portanto, deve cultivar a tranquilidade espiritual para que seu filho receba esta boa influência e possa ser feliz e sorridente" ("Esteja tranquila ao lidar com o bebê"). Esse cuidado vigilante do mundo emotivo e psíquico dos filhos deve continuar toda a vida: os pais devem ser conscientes de que suas atitudes têm uma influência, muitas vezes sutil, sobre o psiquismo deles. Em uma coluna com o título "Meu filho não quer comer," Soares lida com o problema da inapetência das crianças, mas não a partir de considerações biológicas ou físicas, mas da personalidade, do mundo afetivo e psíquico. A responsabilidade está, mais uma vez, centrada na mãe, sob suspeita de ser causante do problema, e responsável de mudar a conduta do filho sem castigos nem recompensas, através de estratégias persuasivas, que o estimulem sem forçá-lo.

Palmer aconselha como lidar com as crianças e os consumos culturais modernos, por exemplo, com a televisão: em lugar de proibir ou restringir excessivamente seu uso, recomenda orientar aos filhos a um uso pedagógico e lúdico, assistindo programas infantis, jogos de futebol, músicas e deixando de lado novelas e programas de horror. Por seu lado, Soares comenta um livro, de autora norte-americana, no qual "aprende-se como ensinar às crianças a respeito do mais complexo dos sentimentos humanos," "amor": o texto cria uma linguagem adaptada à compreensão e à sensibilidade infantil que, de modo experimental, combina simplicidade com um vasto mundo emocional ("Explicando para as crianças: amor").

Consciente da centralidade do discurso dos direitos da criança nesses anos, Palmer observa que ele implicou uma transformação do paradigma educativo em direção a "um tratamento mais afável, muito mais democrático." No entanto, afirma: "a criança deve compreender que no mais velho existe um ser que lhe é hierarquicamente superior em experiência e conhecimento. E que deve acatar seus conselhos, se bem que os possa por em discussão, de maneira cortês" ("Século da criança"). A mudança nos modelos familiares e de educação, agora baseada no diálogo e na compreensão mutua, não implica a eliminação das hierarquias familiares e etárias, mas a possibilidade de colocar em questão os parâmetros e as regras de autoridade anterior. 


\section{Conclusão: infância e experimentação, gênero e escrita}

Nas cartas e nas colunas destinadas ao público feminino escritas por Lispector, a infância revela uma ambivalência entre um modelo convencional da criança e uma linguagem e uma perspectiva experimental em um sentido tanto estético quanto dos modelos familiares. A infância constitui um território desconhecido e um mistério a ser explorado pela mãe e pela escritora, ao mesmo tempo que núcleo de uma linguagem comercial e do consumo que responde ao horizonte de expectativas da imprensa diária. Embora sensível às convenções sociais sobre o papel da mulher como esposa e mãe de família, Lispector não teve embaraço em expressar as dificuldades e até certa estranheza diante da maternidade. Suas cartas revelam uma sensibilidade dupla, como mãe atenta e preocupada com o cuidados dos filhos e como escritora: a partir de uma perspectiva estética e experimental, ela investiga o psiquismo e a expressão dos filhos, como seres espontâneos, escritores potenciais, com capacidade criativa própria.

Lispector foi leitora de uma bibliografia transnacional e cosmopolita que ressaltou a importância da exploração da subjetividade dos filhos e refletiu sobre sua educação, sua sexualidade, sua conduta e pensamento. Ela foi consciente da transformação dos modelos de criança, que propunham abandonar atitudes autoritárias e privilegiavam a confiança e a compreensão dos filhos. Embora suas colunas femininas apresentem um papel de mulher convencional, ligado com a maternidade e com o âmbito doméstico, trata-se de uma mãe moderna, guiada pelas tendências cosmopolitas, inserta na sociedade de consumo, capaz de autoanálise e consciente de suas escolhas. Ela é altamente reflexiva no que diz respeito aos seus filhos: está informada sobre o cuidado de sua saúde física, alimentação, crescimento e é uma consumidora esperta de todo tipo de bens destinados ao consumo infantil. Ela incorpora as teorias pedagógicas e psicológicas da época: questiona a educação tradicional e propõe pensar a criança como um exercício de exploração, descoberta e participação na vida do filho, e um estímulo à sua personalidade. Desse modo, a maternidade é concebida como prática experimental, cujo objetivo é o desenvolvimento do potencial das crianças, capaz de assegurar sua bem sucedida inserção em uma sociedade regulada pela iniciativa individual. Nesse marco, a mãe deve ser uma verdadeira psicóloga ao interior do lar, uma pesquisadora de suas manifestações psíquicas, 
ao mesmo tempo encarregada de descobrir e responsável por solucionar seus principais dilemas. Sem eliminar totalmente as hierarquias familiares e etárias e sem transgredir os papéis tradicionais de gênero, as colunas propõem uma perspectiva experimental para lidar com as crianças, a partir da compreensão, do diálogo, que busca investigar e descobrir aos filhos como verdadeiros mistérios ao interior do âmbito doméstico.

\section{Obras citadas}

Arêas, Vilma. Clarice Lispector com a ponta dos dedos. Companhia das Letras, 2005.

Barbosa, Marialva. História cultural da Imprensa. Mauad, 2007.

Bassanezi Pinsky, Carla. "Mulheres dos anos dourados." História das mulheres no Brasil, editado por Mary Del Priore, Contexto, 1997, pp. 607-39.

Berquó, Elza. "Arranjos familiares no Brasil: uma visão demográfica." História da vida privada no Brasil, vol. 4, editado por Lilia Schwarcz, Companhia das Letras, 1998, pp. 411-37.

Brites, Olga. "Crianças de revistas 1930-1950." Educação e Pesquisa, vol. 26, no. 1, 2000, pp. 161-75.

De Luca, Tania Regina. "A grande imprensa na primeira metade do século XX." História da imprensa no Brasil, editado por Tania Regina de Luca e Ana Luiza Martins, Contexto, 2012, pp. 149-75.

—. "Mulher em revista." Nova história das mulheres no Brasil, editado por Carla Bassanezi Pinsky e Maria Joana Pedro, Contexto, 2013, pp. 447-68.

Dinis, Nilson. Perto do coração criança: imagens da infância em Clarice Lispector. U Estadual de Londrinas, 2006.

Josiowicz, Alejandra. "La escritora que mató a los peces: escritura, género y mercado en Brasil (1967-1978), un estudio de la literatura infantil de Clarice Lispector." Revista Iberoamericana, vol. 79, no. 244-45, 2013, pp. 899-916.

-. "Transformaciones de la infancia y el género en Clarice Lispector." La cruzada de los niños: intelectuales, infancia y modernidad literaria en América Latina. U Nacional de Quilmes, 2018, pp. 181-226.

Lima, Nísia Trindade, e Gilberto Hochman, "Pouca saúde e muita saúva': sanitarismo, interpretações do país e ciências sociais" Cuidar, controlar, 
curar: ensaios históricos sobre saúde e doença na América Latina e Caribe, editado por Gilberto Hochman e Diego Armus, Fiocruz, 2004, pp. 493-533. Lispector, Clarice. “A criança independente.” Diário da noite, 20 out. 1960.

—. "A criança persegue o perigo.” Correio da Manhã, 15 jul. 1960.

—. "A entrevista alegre." Jornal do Brasil, 30 dez. 1967, Caderno B.

—. "A moda." Diário da noite, 24 abr. 1969.

—. "A mulher e o preconceito." Correio da Manhã, 16 mar. 1960.

—. "A mulher esclarecida." Correio da Manhã, 21 ago.1959.

—. "Amizade valiosa." Correio da Manhã, 22 jul. 1960.

-. Correio feminino. Editado por Maria Aparecida Nunes, Rocco, 2006.

- Correspondências/Clarice Lispector. Editado por Teresa Montero. Rocco Digital, 2015.

—. "Dia das mães." Diário da Noite, 7 mai. 1960.

—. "Educação dos filhos." Correio feminino, 8 abr. 1960.

—. "Educação.” Correio da Manhã, 10 ago. 1960.

—. "Elas também querem a moda." Diário da Noite, 30 jan. 1961.

—. "Esteja tranquila ao lidar com o bebê." Correio feminino, 07 set. 1960.

—. "Explicando para as crianças: amor." Diário da noite, 26 jun. 1960.

—. "Filhas modernas e rebeldes." Correio da Manhã, 15 dez. 1959.

—. "Importante descoberta." Correio da Manhã, 19 ago. 1960.

—. Minhas queridas. Editado por Teresa Montero, Rocco, 2007.

—. "Na hora da aflição, o que você faria?” Diário da Noite, 14 e 22 jul. 1960.

—. "Século da criança." Correio feminino, 18 jan. 1961.

—. "Ser mãe." Correio da Manhã, 9 set. 1959.

- Só para mulheres: conselhos, receitas e segredos. Editado por Maria Aparecida Nunes, Rocco, 2008.

Lobo, Luiza. "Feminism or the Ambiguities of the Feminine in Clarice Lispector." Closer to the Wild Heart: Essays on Clarice Lispector, editado por Claudia Pazos Alonso e Claire Williams, Oxford UP, 2002, pp. 90-105.

Mendes de Sousa, Carlos. "Mother, Body, Writing: The Origins and Identity of Literature in Clarice Lispector." Closer to the Wild Heart. Essays on Clarice Lispector, editado por Claudia Pazos Alonso e Claire Williams, Oxford U P, 2002, pp. 9-27.

Méndez, Mariela. Crónicas travestis: el periodismo transgresor de Alfonsina Storni, Clarice Lispector y María Moreno. Beatriz Viterbo, 2017. 
Moser, Benjamin. Why This World: A Biography of Clarice Lispector, Oxford UP, 2009.

Nunes, Aparecida Maria. Clarice Lispector jornalista: páginas femininas \& outras páginas. Senac, 2006.

Peixoto, Marta. Passionate Fictions: Gender, Narrative and Violence in Clarice Lispector. U of Minnesota P, 1994.

Russo, Jean. "The Social Diffusion of Psychoanalysis during the Brazilian Military Regime: Psychological Awareness in an Age of Political Repression." Psychoanalysis and Politics: Histories of Psychoanalysis under Conditions of Restricted Political Freedom, editado por Mariano Ben Plotkin e Joy Damousi, Oxford UP, 2012, pp. 166-84.

Santos, Tania Coelho dos. "O movimento psicanalítico e a difusão da psicanálise no Brasil.” Tempo Psicanalítico, vol. 29, 1997, pp. 171-89.

Wasserman, Renata Ruth Mautner. Central at the Margin: Five Brazilian Women Writers. Bucknell UP, 2007.

-. "Trabalho de mulher: dois contos infantis de Clarice Lispector." Revista de Crítica Literária Latinoamericana, vol. 20, no. 40, 1994, pp. 43-52.

Williams, Claire. "Which Came First? The Question of Maternity in Clarice Lispector's 'O ovo e a galinha." Women, Literature and Culture in the Portuguese-Speaking World, editado por Cláudia Pazos Alonso, Mellen, 1996, pp. 135-53. 